\title{
Prospects looking up for new remote-sensing satellite
}

Washington

AfTER months of delays and political wrangling, plans for Landsat 6, the new remote-sensing satellite destined to replace the ageing Landsats 4 and 5, seem ready to move ahead. Late last month, EOSAT, the commercial entity established by the government to operate the Landsats, and the National Oceanic and Atmospheric Administration (NOAA) reached an agreement that will permit Landsat 6 to be launched aboard an Air Force Titan II rocket by spring of 1991.

A year ago, the next generation of Landsats seemed to be going nowhere (see Nature 325, 187; 1987). Congress and the Reagan administration were at loggerheads over how large the government subsidy to EOSAT should be. The administration has pushed hard to move the financial burden for providing remotesensing service to the commercial sector. But EOSAT has maintained that the government had made a commitment to providing funds for launches at least through Landsat 6.

Although the plan agreed by NOAA and EOSAT must still be approved by Congress and the White House Office of Management and Budget, both NOAA and EOSAT are confident of success.

Congressman Robert Roe (Democrat,

\section{Earnings up}

\section{London}

BRITISH universities continue to become less dependent on block grants direct from the Department of Education and Science. Provisional figures compiled for the University Grants Committee (UGC), released two weeks ago, show that earnings for research and other services increased by more than $£ 90$ million in $1986-87$ compared with the previous year to a total of $\mathfrak{6 6 3 5}$ million - a 13 per cent increase in real terms. Of the earnings, 49 per cent came from non-government sources (mainly industry, commerce and charities), compared with 37 per cent in 198182. Direct income from the research councils rose by 7 per cent in real terms to $£ 180$ million between $1985-86$ and 1986 87. During the same period, increases were achieved in income from industry and commerce (up 10 per cent to $£ 68$ million), charities (up 23 per cent to $£ 93$ million) and short courses for industry and other bodies (up 16 per cent to $£ 47$ million). These increases in external revenue mean that in 1986-87 the government's block grants to universities amounted to 55 per cent of their total recurrent income, compared with 77 per cent in $1974-75$.
New Jersey), chairman of the Committee on Science, Space, and Technology, says the new arrangement "removes the uncertainty hanging over our remote-sensing program and enables EOSAT to remain competitive in the international arena". NOAA will provide EOSAT with $\$ 220$ million to build the satellite and establish the necessary ground links. But EOSAT has agreed to pay back $\$ 10.8$ million from its marketing revenues at the rate of $\$ 2.5$ million per year. NOAA also persuaded the Air Force to launch Landsat 6 for $\$ 36.5$ million, approximately $\$ 10$ million less than the amount originally requested for launch services.

The concern now will be the hiatus in service between the demise of Landsat 4 and 5 and the arrival of Landsat 6. By 1991 the satellites will be in their eighth and ninth years in orbit, and both had a design life expectancy of only three years. EOSAT is husbanding the two satellites' resources, but a gap in coverage now seems inevitable.

Landsat 6 will have a thematic colour mapper similar to those carried on earlier Landsats, with $30-\mathrm{m}$ resolution. It will also have an additional $15-\mathrm{m}$ resolution panchromatic channel easily superimposable on the colour images. This still leaves Landsat's capability behind the $10-\mathrm{m}$ resolution available from SPOT, the French remote-sensing satellite. But if financial support can be found, EOSAT will also put sensors capable of resolving objects to $5 \mathrm{~m}$ on board the new satellite.

Another instrument that may get a ride aboard Landsat 6 is the Sea Wide Field Sensor being developed by the National Aeronautics and Space Administration (NASA). Sea WIFS, as the sensor is known, is an improved version of the Coastal Zone Color Sensor that flew aboard Nimbus 7. It measures sea colour changes caused by phytoplankton pigments, chiefly chlorophyll $\mathrm{A}$, and is needed for the global ocean flux study sponsored by the National Science Foundation.

The future of Landsat 7 is less certain. Both Congress and the Reagan administration support an additional satellite. NOAA has awarded contracts to KRS Remote Sensing, a division of Eastman Kodak, the Analytical Sciences Corporation and the Egan Group to conduct comprehensive studies of how a new satellite should be configured. EOSAT is conducting its own study, and will make an independent proposal for Landsat 7. It is clear that the administration will look favourably on proposals that shift even more of the cost of the satellites onto the private sector.

\section{ESA's Olympus set to launch a new satellite era}

\section{London}

FORTY educational institutions from ten countries have been selected to participate in a distance-learning experiment using the pioneering Olympus-1 satellite of the European Space Agency (ESA). British interest in the Olympus programme is riding particularly high: ESA's optional telecommunications programme is one on which the British government is sufficiently keen to spend around $£ 20$ million annually. The Olympus programme, which started in 1979 , will cost an estimated $£ 400$ million, of which Britain will contribute $\mathbf{4 0}$ per cent. British Aerospace has taken the lead in the satellite's design and construction. Olympus, which started life under the title L-Sat (for 'large satellite') is aimed at identifying key satellite technologies for the next decade.

Olympus-1, whose launch is scheduled for January next year (some 18 months later than originally planned, although no reason has been given for the delay), is described as a 'technology demonstration', and will be followed by a family of multi-purpose communications satellites that will be among the world's largest and most powerful.

For Olympus-1, a total of 3,000 hours a year will be made available for education, with Britain's share at 1,150 hours for the 23 British institutions selected. The services will be provided free for the first two years, after which a nominal fee will be required. The types of exercise for which Olympus will be used include language learning by establishing multilingual video magazines between nations and live transmission of medical conferences. The largest single interest shown has been in broadcasting films or video. Allocation of time for new business services will be made by ESA. The agency has identified the corporate training and educational services as having the greatest potential for expanding satellite use in the next decade.

Olympus-1, which with a launch mass of $3,300 \mathrm{~kg}$ will be the largest-ever multiple communications satellite, will have three payloads. The first will allow transmission of multiple beams in the $12-14 \mathrm{Ghz}$ range, for data transmission experiments and multi-location video conferencing; the second will allow experimentation in the 20-30 Ghz range, the so-called 'frequency of the future', with possible uses in aircraft communications and electronic newsgathering; and the third will allow direct broadcasting, with two high-powered television channels for broadcasting across most of western Europe. Simon Hadlington 